\title{
The Effect of Expired Acyclovir and Omeprazole Drugs on the Inhibition of Sabic Iron Corrosion in HCl Solution
}

\author{
M. Abdallah ${ }^{1,2, *}$, A. Fawzy ${ }^{1,3}$, A. Al Bahir ${ }^{1,4}$ \\ ${ }^{1}$ Chemistry Department, Faculty of Applied Science, Umm Al-Qura University, Makkah, Saudi \\ Arabia \\ ${ }^{2}$ Chemistry Department, Faculty of Science, Benha University, Benha, Egypt \\ ${ }^{3}$ Chemistry Department, Faculty of Science, Assiut University, Assiut, Egypt \\ ${ }^{4}$ Chemistry Department, Faculty of Science, King Khalid University, Abha, Saudi Arabia \\ *E-mail: metwally555@yahoo.com
}

doi: $10.20964 / 2020.05 .86$

Received: 13 Janaury 2020 / Accepted: 18 March 2020 / Published: 10 April 2020

\begin{abstract}
Acyclovir (ACV) and Omeprazole (OMP) are two expired drugs examined as an inhibitors for the dissolution of Sabic iron in $1.0 \mathrm{M} \mathrm{HCl}$ using weight loss, electrochemical impedance and two types of polarization; galvanostatic and potentiodynamic measurements . Increase the concentration of expired ACV and OMP increases the efficacy of inhibition that also decreases with temperature. These drugs acts as mixed inhibitors that was detected by galvanostatic polarization studies. The inhibition activity of ACV and OMP owing to its horizontal adsorption of them on the Sabic iron surface because of the presence of several active centers. The adsorption follows Langmuir isotherm. The impedance data demonstrated one capacitive loop suggesting that the charge transfer control the corrosion reaction. The expired ACV and OMP performed as an efficient pitting corrosion inhibitor by moving the pitting potential to more noble values.
\end{abstract}

Keyword: Sabic iron; Expired drugs; Corrosion Inhibitors; Kinetic parameters; Pitting potential

\section{FULL TEXT}

(C) 2020 The Authors. Published by ESG (www.electrochemsci.org). This article is an open access article distributed under the terms and conditions of the Creative Commons Attribution license (http://creativecommons.org/licenses/by/4.0/). 